\title{
让音乐的幸福能量在学生生命里传递
}

任婕

苏州工业园区青剑湖学校

DOI:10.32629/jief.v2i7.2002

[摘 要] 音乐除了给人美的享受外，更给人们的生活带来无限的幸福能量，作为音乐教师，我们该成为这种能量的播种者，带孩子们在音乐 的殿堂里幸福驰骋。

[关键词] 音乐; 幸福; 教育

中图分类号：G623 文献标识码：A

作为一名音乐教师，我一直认为音乐是有幸福能量的，只要我们细 心挖掘, 这种幸福能量的传递无处不在。

1 让学生通过音乐领悟音乐的内在含义

音乐有着自身神奇的鬼力，音乐是我们无形中的 “伴儿”，因为有了 这个伴儿, 让人感到放松, 心情舒畅, 对于成长中需要朋友陪伴的孩子们 来说, 在音乐的学习学习中体验到不一样的成长快乐。教师要智慧的引领 学生在音乐的学习中去感悟, 学生可以通过聆听欣赏音乐, 尝试听懂每首 音乐的内在含义，能够有自己的感受、体会，净化心灵，陶冶情操。

\section{2 让学生通过音乐感悟生命中的正能量}

音乐的学习随着孩子的年龄增长也在给孩子不一样的人生感悟。在 二二年级的教学中, 老师们主要以 “唱游课” 为主。通过学生的模唱、 模仿等环节, 亲身体验音乐的愉悦过程, 从而达到课堂中享受音乐, 理 解音乐的感性特征与精神内涵。如: 苏教版一年级上册课本中 《不能告 诉你》一课, 老师想让孩子们既能很好的学会歌曲的演唱也能从中知道 正确学做雷锋的观念。在简单介绍雷锋的事迹之后, 就要问问孩子们: “你们觉得身为在校学生的你能为班级做哪些好事呢？”一个孩子回答并 作出相应劳动动作后: “请同学们跟他一起学习一下吧 (边说边做动作: 小桌子, 我擦的)”这就是模仿学习。

在有了四个不同劳动形式之后, 可以尝试 “开火车” 劳动或者合作 劳动, 这就是合作的学习。

当然, 少不了唱了: “看到同学们合作劳动的场面, 老师既感动又欣 慰, 不禁得唱起来, 请你跟我学一学:

$$
\begin{aligned}
& \begin{array}{llll|llll|llll|ll|}
\underline{5} & 6 & \underline{5} & 6 & \underline{5} & 6 & \underline{5} & 3 & \underline{2} & 1 & \underline{2} & 3 & 5 & 0
\end{array} \\
& \text { 学习雷锋做好事啊, 不能告诉你。”这就 }
\end{aligned}
$$

是模唱的学习。如此课堂, 有体验劳动的欢乐, 有合作的凝聚, 还有歌 唱的美妙。

随着孩子年龄的增长，不同年级设置了不同音乐课内容，包括感恩 父母的歌曲的学习, 包括爱国歌曲的赏析等等, 生命的正能量在学生的 生命中传递。

\section{3 在音乐课上挖掘学生的潜能}

在三四年级的教学中, 通过低年级的音乐体验和感受, 已经能准确 判断乐曲的情绪。相较于低年级而言, 中年级的教学中, 学生各方面能 力的增强, 老师与学生之间的沟通会更加有意思。老师在课中涉及很多 其他课外的知识, 会让学生大开眼界, 也有很多与其他学科融会贯通, 真正做到知识的多样化。如: 苏少版三年级上册第五单元：读唐诗, 这 个单元中大多是学生们学过的诗歌, 学生们听到自己熟悉的唐诗变成歌 曲, 着实感兴趣, 就连平时上课喜欢开小差的同学也会摇头晃脑地跟着 唱。这就是音乐的吸引力。

老师在教学中, 在学生基本能力之上进行培养和提高, 又是会有意 外收获。我在中年级的教学, 更多时候会有情境的导入, 这些都不如让 学生自己聆听, 同时自己编故事。在四年级上册中有《鳟鱼》这一课, 我就运用的了这个方法。

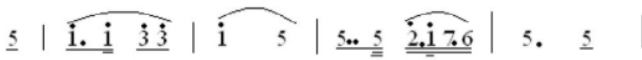

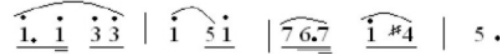

老师引入: “一位渔人看今天天气不错, 准备去钓鱼。请你聆听音乐, 想象你看到了什么情景？”学生一定会给我很完美的答案：“看到了神气 的渔夫，自由的鱼儿，晴朗的天空 ......”老师看似找茬地问: “你能听 出分别是什么乐器代表着你们说的内容呢? 主角是谁? ” 学生不自信没 关系, 带着问题再听一次, 这一次, 既解决了音乐的伴奏乐器问题, 又 解决了主奏乐器的问题, 甚至还为后面情节的变化做出了铺垫。真是一 举多得啊。

如此看来, 中年级的课堂, 老师需要加入更多让学生自己加入课堂 的手段, 不断地引导和 “制造问题”, 学生才能更好地发挥自己的想象, 挖掘自己的潜能。

同时, 不仅如此, 中年级的同学在有了一定乐理知识的前提下, 开 始了小乐器的学习, 这更加激发学生学习音乐的兴趣, 为高年级的提高 打下了基础。

\section{4 在音乐的学习中发挥学生的的和创造力}

五六年级的高年级同学，随着身心的发展，大多的情况都只是在默 默地听。男生由于开始变声, 不太愿意唱歌, 女生也开始变得羞涩, 不 愿意与老师互动, 这样的课堂对于音乐课而言只有一个字可以形容, 那 就是, 地。出入高年级课堂的我, 总是一不小心就我课堂变成了独角戏。 还好我们有了新的沟通桥梁: 小乐器——坚笛。

三四年级引入坚笛是为了能够增加音乐的趣味性, 也对学生在歌唱 中的音准、节奏, 都是很有帮助的。在学习两年之后, 很多同学几乎能 够做到陌生的乐谱拿到手练习两三遍就能够完成, 毫无压力。于是, 我 开始了给学生的一个全新体验一一创作。

“同学们, 在我们的集思广益之下, 我们班级创作的歌曲的第一句完 成了。这就是创作, 通过这个方式就是告诉大家, 创作其实并不难, 我 们只需要把问题分解，一步步解决，这就能成为一首完整的作品。”

在音乐教育中时长会有孩子们自己创作的作品问世, 虽然他们的创 作还很稚嫩, 还需要历练。但让我欣慰的是, 音乐给他们的生活带来了 另一份乐趣。

音乐是一门特殊的学科, 既能陶冶情操, 有可激发创造, 作为教师 我们应该努力做一个幸福的课堂开发者, 让音乐的幸福能量在学生生命 里传递, 让音乐的幸福能量伴随孩子的一生。

\section{[参考文献]}

[1] 尉转琴.关于初中音乐课堂教学师生互动问题的分析 [J].新课 程,2020(37):57.

[2] 李清钜.立德树人视域下初中音乐教学策略谈 [J]. 新课 程,2020(37):105.

[3]马雯丹.浅谈初中音乐教学如何激发学生学习兴趣[J].新课 程,2020(37):210.

作者简介：任婕（1993-)，女，汉族，江苏常州人; 本科，二 级教师; 研究方向：音乐教育; 从事工作：小学教师 